\title{
ACESSO À JUSTIÇA E APLICAÇÃO DE PRECEDENTES NO BRASIL: EM BUSCA DE UMA CULTURA JURÍDICA CONSTITUCIONALMENTE ADEQUADA
}

\author{
ACCESS TO JUSTICE AND APPLICATION OF PRECEDENTS IN \\ BRAZIL: IN SEARCH OF A CONSTITUTIONALLY SUITABLE LEGAL \\ CULTURE
}

\author{
Karinne Emanoela Goettems dos Santos ${ }^{1}$ \\ Catharina Fortuna de Mesquita ${ }^{2}$
}

\section{RESUMO}

O Código de Processo Civil brasileiro, promulgado no ano de 2015, fortaleceu a aplicação dos precedentes no país, instituto naturalmente construído no âmbito da tradição jurídica common law, que se distingue da tradição jurídica civil law com a qual o Brasil se vincula. A partir disso, a mera normatização apresentada pelo novo CPC não é suficiente compreender a racionalidade do sistema de precedentes no Brasil e tampouco para viabilizar a sua aplicabilidade. Diante disso, o presente trabalho pretende compreender as razões que justificam a recepção de um sistema de precedentes no Brasil e qual a sua racionalidade, sobretudo no âmbito do acesso à justiça, no que respeita à efetividade do processo judicial. Ao final, valendo-se do método hipotético-dedutivo, espera-se demonstrar que a natureza da aplicação dos precedentes deve necessariamente guiar-se pelo devido processo legal e demais princípios constitucionais, em respeito à tradição histórica e à identidade brasileira, bem como provocar uma maior participação do ensino jurídico, chamando a ética profissional à sua responsabilidade e participação como contributos à efetividade e do acesso à justiça.

\section{PALAVRAS-CHAVE:}

Acesso à Justiça. Precedentes. Common law. Civil law. Racionalidade. Ensino Jurídico.

\begin{abstract}
The Brazilian Code of Civil Procedure, promulgated in 2015, strengthened the application of precedents in to country, an institute naturally built under the common law legal tradition, which is distinguished from the civil law legal tradition with which Brazil is linked. From this, the simple standardization presented by the new CPC is not enough to understand the rationality of the precedent system in Brazil, nor to make its applicability viable. In view of this, the present work intends to understand the reasons that justify the reception of a system of precedents in

\footnotetext{
${ }^{1}$ Doutora e Mestre em Direito pela UNISINOS. Professora Adjunta da Faculdade de Direito da Universidade Federal de Pelotas (UFPEL). Coordenadora do Serviço de Assistência Jurídica da UFPEL. Coordenadora do Grupo de Pesquisa Acesso à Justiça no século XXI: o tratamento dos conflitos na contemporaneidade.

2 Advogada. Pós-graduanda em Direito Agrário e Agronegócio pela Fundação Escola Superior do Ministério Público - FMP.
} 
Brazil and what is its rationality, especially in the scope of access to justice, with regard to the effectiveness of the judicial process. In the end, using the hypothetical-deductive method, it is expected to demonstrate that the nature of the application of the precedents must necessarily be guided by the due legal process and other constitutional principles, respecting the historical tradition and the Brazilian identity, as well as provoking greater participation in legal education, calling professional ethics its responsibility and participation as contributions to effectiveness and access to justice.

\section{KEYWORDS:}

Access to Justice. Precedents. Common law. Civil law. Rationality. Legal Education.

\section{INTRODUÇÃO}

O Código de Processo Civil de 2015 instaurou uma lógica de julgamentos em busca da harmonização da jurisprudência, atualmente discutida em torno de uma cultura de aplicação dos precedentes. A partir disso, é preciso buscar compreender qual racionalidade sustenta o modo de aplicação deste instituto, tradicionalmente utilizado pela tradição jurídica do common law, e se tal racionalidade se mostra adequada ao modelo constitucional de jurisdição, preconizado pela Constituição Federal de 1988.

Na perspectiva de Mauro Cappelletti e Bryant Garth (1988, p.12), a mera proclamação de direitos de nada serve se não houver um sistema de justiça adequado para que tais direitos possam ser legitimamente reivindicados, o que faz do acesso à justiça o mais elementar direito humano. Nesta perspectiva, é preciso analisar se a adoção de precedentes no Brasil, a partir do novo CPC, guarda adequação com a efetividade inerente ao direito de acesso à justiça, sobretudo no que se refere à legitimidade dos procedimentos regulados pelo Estado e colocados à disposição do cidadão no sistema de justiça.

Assim, primeiramente, serão investigadas as origens da tradição jurídica do common law, alicerçada na aplicação de precedentes, a partir de uma breve análise histórica, com destaque para a evolução da utilização dos precedentes no âmbito desta tradição jurídica, até o alcance de sua função vinculante. Passo seguinte, serão expostos os elementos que desenham a tendência de convergência entre as tradições jurídicas common law e civil law, e, a partir dela, 
a valorização dos precedentes como fundamento da decisão judicial. O problema da discricionariedade é destaque nesta abordagem, dada a preocupação de ambas as tradições jurídicas acerca da dispersão de decisões distintas sobre casos semelhantes.

Com a adoção do método hipotético-dedutivo, este trabalho, assim, pretende destacar a necessidade de adequação do uso de precedentes ao contexto brasileiro, o que, para além da mera e desarrazoada importação de institutos estrangeiros, supostamente mais éticos e legítimos, necessita de uma reorganização da cultura jurídica interna. Isso porque a compreensão e a interpretação são fenômenos particularmente realizados e interpelados pela tradição, levando em consideração seus elementos temporais e históricos (GADAMER, 2006, p.68-69), o que revela a importância da construção de uma racionalidade adaptada à cultura jurídica brasileira.

Para tanto, qualquer renovação ou adaptação da tradição jurídica aos novos tempos deve levar em consideração o perfil do ensino jurídico. Nessa toada, o presente trabalho defende a construção de uma racionalidade de aplicação dos precedentes constitucionalmente adequada, com coerência e integridade, na linha do que foi inaugurado e preconizado pelo Código de Processo Civil de 2015, bem como a partir de uma perspectiva de ensino jurídico que realmente assegure a ética profissional necessária para contribuir com a efetividade dos direitos no âmbito do acesso à justiça.

\section{A EVOLUÇÃO DO PRECEDENTE NA TRADIÇÃO JURÍDICA COMMON LAW}

Inicialmente, é importante pontuar duas premissas elementares para a análise da evolução dos precedentes na tradição jurídica common law: a primeira é de que o direito inglês (positivismo jurídico) e o direito norte-americano (realismo jurídico), ${ }^{3}$ muito embora estejam assentados em dinâmicas distintas de aplicação do common law, possuem muito mais elementos de conexão, de modo que, juntos, compõem uma base para a análise de uma racionalidade

\footnotetext{
${ }^{3}$ O pragmatismo norte-americano pode ser observado pela perspectiva de Benjamin Cardozo, ex-ministro da Suprema Corte dos EUA. Ver em: CARDOZO, Benjamin N. A natureza do processo judicial. São Paulo: Martins Fontes, 2004, p.105-133).
} 
acerca dos precedentes (NUNES;VIANA, 2018, p.37); a segunda premissa está na importante distinção entre a tradição jurídica common law e o próprio sistema de precedentes.

Expostas as premissas, o passo seguinte é acompanhar a linha histórica de formação do common law e da evolução do precedente dentro desta tradição jurídica, profundamente marcada pela história do direito inglês" (DAVID, 1996, p. 279).

\subsection{As fases históricas da common law: da dispersão à adoção de precedentes}

Rene David (1996, p. 285) apresenta a história do direito inglês em quatro sucessivos períodos. ${ }^{4} \mathrm{O}$ primeiro período é do direito anglo-saxônico, que se situa no medievo entre a queda do império romano e a conquista normanda em 1066, em que o direito não era aplicado uniformemente em todo o seu território, com preponderância das regras locais. O segundo período é marcado pela invasão dos normandos no território inglês, em 1066, e se estende até 1485, momento a partir do qual é possível observar a origem do common law como direito comum aplicável a todo o reino. O terceiro período está entre 1485 e 1831 e é caracterizado pela convivência simultânea do common law e a equity. O último período, chamado de moderno, parte de 1832 até os dias atuais.

Desse cenário histórico, destaca-se a invasão normanda, em 1066, que provoca o fortalecimento do poder real que culminou com a criação de cortes reais, chamadas de Tribunais Reais de Justiça, então responsáveis pela análise de casos que tivessem relação com os interesses da coroa, aplicando o direito denominado de common law (CRAMER, 2016, p. 14$15)$.

O common law, assim, surgiu para o julgamento de conflitos relacionados à coroa, em oposição aos costumes locais, com aplicação em todo o território inglês (DAVID, 1996, p. 286). Os costumes locais, por sua vez, eram julgados pelas cortes locais, que podiam ser de jurisdição eclesiástica, municipal ou comercial, dependendo da matéria a ser analisada (DAVID, 1996, p. 286). De acordo com Aurélio Viana e Dierle Nunes (2018, p.43), nesse segundo período em que a common law se solidificou, o direito inglês foi marcado fortemente pelos seus traços

\footnotetext{
${ }^{4}$ Muito embora a precisão cronológica não seja exata, didaticamente pode ser usada como ponto de partida para melhor compreensão das especificidades inerentes à tradição jurídica em comento e sua evolução.
} 
processuais, voltado para a solução prática dos litígios, diferentemente do direito europeu, que seguiu a sistematização de suas normas com base no direito romano.

Em 1258, as Provisões de Oxford proibiam a criação de novos writs. No mesmo ano, o Statute of Westminster II, passou a permitir a emissão de writ, desde que se estivesse diante de um caso similar anterior, reclamando, assim, a coerência entre os casos decididos e os casos a decidir, pré-anunciando a técnica de cotejamento de casos com decisões pretéritas (VIANA; NUNES, 2018, p.44-46). ${ }^{5}$ Assim, muito embora sua essência já possa ser observada no século XIII, diante das tensões entre rei e barões, o uso do termo precedente somente ocorreu em 1557 (VIANA; NUNES, 2018, p.44).

Para Daniel Mitidiero (2017, p. 28), “a invocação do precedente pelos juízes, porém, dava-se com o intuito de simples ilustração ou explicação do significado do Direito aplicado ao caso", não havendo, pois, obrigatoriedade em sua observância. O precedente possuía, portanto, uma função meramente ilustrativa, que servia para demonstrar o direito "que os juízes citavam em suas decisões” (MITIDIERO, 2017, p. 30), sem, portanto, servir como critério decisório.

Aos poucos, os Tribunais reais foram ampliando sua competência, o que era vantajoso para a corte, uma vez que o acesso à justiça era cobrado, proporcionando lucros à coroa (DAVID, 1996, p. 286-288). Por outro lado, os processos da common law apresentavam demasiada rigidez, com regras tão técnicas e complexas que acabavam, muitas vezes, por afastar a possibilidade de dar a solução justa ao caso concreto. Com o declínio das cortes locais e a ampliação dos julgamentos da common law, foi necessário, então, a criação de alternativas para flexibilização dos procedimentos (DAVID, 1996, p. 294-295, 309). A solução encontrada foi a possibilidade de recurso ao Chanceler que, após analisar o caso, se houvesse interesse real, encaminhava o pedido ao rei, reconhecido como o arauto da justiça.

Para Viana e Nunes (2018, p.48, nota de rodapé 84), certamente a concessão de medidas justas por parte do rei também se configuravam em instrumentos de governo, "mas o caráter ambivalente refere-se à maleabilidade no julgamento dos casos, sob a justificativa de fazer o bem ao povo".

\footnotetext{
5 É importante considerar também, neste segundo período, a superveniência da Magna Carta (1215), que representou limitações ao poder real, no que respeita à tributação e aos julgamentos dos tribunais reais.
} 
Com o passar do tempo, o Chanceler foi ganhando autonomia e, em 1529, o cargo era ocupado, em regra, por juristas, e suas decisões, inicialmente tomadas pela equidade do caso concreto, tornaram-se cada vez mais sistemáticas, tornando as decisões equitativas corretivos aos princípios jurídicos aplicados pelos Tribunais Reais (DAVID, 1996, p. 296). O Tribunal do Chanceler, objetivava, portanto, um aperfeiçoamento moral às decisões aplicadas pelas Cortes Reais e as regras complementares por ele proferidas passaram a ser denominadas de equity.

A transformação social do final da Idade Média, bem como a falta de compilação de precedentes, aliada à ampliação dos tribunais de equity, desgastaram o modelo da common law. Contudo, em 1628, o fôlego é retomado a partir da organização dos casos julgados por Edward Coke, por meio da obra Institutes of the laws of Englands, que reorganiza o direito inglês e o toma como base dos julgamentos até os dias atuais (VIANA; NUNES, 2018, p.51-52).

É, porém, apenas nos séculos XVI e XVII que o precedente passa a ser utilizado de maneira persuasiva, ou seja, começa "a servir de critério para decisão do caso, desde que conforme ao Common Law" (MITIDIERO, 2017, p. 31). Nesse período, Blackstone, doutrinador da época, entendia que os juízes deveriam se convencer de que o precedente não era injusto ou absurdo, para que pudessem aplicá-lo. Caso contrário, haveria mistake the law, ou seja, "a solução anterior não era Direito, com o que encarnava simplesmente uma solução equivocada. Com o novo caso, acha-se a sua verdadeira e correta solução, que sempre existiu, não tendo sido apenas anteriormente encontrada" (MITIDIERO, 2017, p. 34).

\subsection{E o precedente adquire a força da vinculação (stare decisis)}

É importante destacar que o uso do precedente com caráter vinculante é recente na história da tradição jurídica common law. Ainda que o precedente determinasse o direito a ser seguido, com sua função persuasiva, sua aplicação estava condicionada ao jugo do julgador, ou seja, não era uma norma propriamente dita. O que se verificava, portanto, era a "abertura de um amplo juízo de conveniência ao juiz" (MITIDIERO, 2017, p. 36).

Diante desse cenário de incerteza ou insegurança, Jeremy Bentham, utilitarista e crítico da common law, abriu uma forte oposição a esse modelo no século XIX, por entender que a sistemática adotada estava marcada por extrema fragmentariedade, desordem e dispersão. 
Como solução, Bentham propôs a alteração do direito por meio da codificação (VIANA; NUNES, 2018, p.73). Contudo, as críticas de Bentham tanto não vingaram como, na verdade, acabaram por reforçar as bases da tradição da common law, atribuindo maior certeza ao uso dos casos anteriores como critério de julgamento. Com isso, os precedentes passam a ser utilizados com caráter vinculante, "capaz de servir aos interesses do Estado e de determinados grupos hegemônicos" (VIANA; NUNES, 2018, p.74), e, assim, preservando ou estabilizando as decisões pretéritas.

E assim passam a se organizar as regras do stare decisis et non quieta movere, por meio do qual se pretenderá não perturbar e manter tal como está o caso já julgado. Contudo, a vinculação aos casos anteriores não era inexorável, pois, em caso de diferenças devidamente apontadas entre o caso a ser julgado e os casos anteriores, o precedente não seria aplicado (distinguishing).

É por isso que, da nova concepção de precedente a partir das regras do stare decisis, como um modelo rígido capaz de sufocar o desenvolvimento do direito, surge em 1966 do século XX uma nova técnica, quando a Câmara dos Lordes determina a superação de precedentes (overruling) "em determinadas situações a fim de não perpetuar soluções injustas e não frustrar a necessária abertura que o direito deve proporcionar para acolher a evolução social” (MITIDIERO, 2017, p. 41).

Portanto, o precedente não se originou com poder de vinculação, pois, na verdade, foi evoluindo em suas funções distintas: ilustrativa, persuasiva e vinculante. Além disso, percebese que as alterações no decorrer dos séculos visaram o controle de arbitrariedades, tendo culminado na "percepção de que o direito é fruto de uma prática interpretativa a partir de fontes dotadas de autoridade" (MITIDIERO, 2017, p. 41).

Por fim, a partir da última década do século XX ocorre uma reforma significativa no direito inglês, marcada pela edição de um Código de Processo Civil em 1999 e pela reorganização do judiciário nos anos 2000, com a instituição da Supreme Court of the United Kingdom (VIANA; DIERLE, 2018, p.40, nota de rodapé 52). ${ }^{6}$

\footnotetext{
${ }^{6}$ Veja-se a relevância de um código de normas ínsito a um sistema de justiça pautado na força criativa do processo e na jurisdição, o que pode ser apontado como ponto de convergência das duas tradições jurídicas.
} 
O fato é que a tradição "common law sempre se estruturou a partir do estrito contato com a história e com a tradição da comunidade em que se formava" (STRECK, ABBOUD, 2013, p. 41), o que contribuiu com a formação da cultura de respeito às decisões proferidas (STRECK, ABBOUD, 2013, p. 41). Desse modo, não são necessárias regras que determinem a obrigatoriedade da aplicação dos precedentes. Esta se fundamenta apenas na ideia de que respeitar os precedentes é um comportamento instintivo, já introjetado na cultural jurídica (CRAMER, 2016, p. 52).

Viana e Nunes (2018, p.107) observam, ainda, que essa nova roupagem da common law e sua vinculação aos seus precedentes revela sobretudo o traço despótico do precedente, a partir de uma clara disputa de poder entre o Parlamento e os Tribunais, especialmente no pós-guerra, em meio a um momento histórico de grande discussão no âmbito jurídico a respeito de padrões decisórios.

Para pontuar a finalização da presente digressão histórica, no sentido de valorizar o contexto histórico e cultural como contributo da organização política e jurídica, bem assinala Ingebord Maus (2000):

Quando a Justiça ascende ela própria à condição de mais alta instância moral da sociedade, passa a escapar de qualquer mecanismo de controle social - controle ao qual normalmente se deve subordinar toda instituição do Estado em uma forma de organização política democrática. No domínio de uma Justiça que contrapõe um direito "superior", dotado de atributos morais, ao simples direito dos outros poderes do Estado e da sociedade, é notória a regressão a valores pré-democráticos de parâmetros de integração social.

E é justamente sob esse viés democrático que se pretende estabelecer uma discussão acerca da racionalidade de padrões decisórios, na qual se inclui o instituto dos precedentes, sobretudo a partir da convergência das tradições jurídicas common law e civil law. Afinal, por que a aplicação dos precedentes chega aos países de tradição civil law, a exemplo do Brasil, de perspectiva histórica e cultural tão diversas? É o que se pretende avaliar no item a seguir. 


\section{A CONVERGÊNCIA DAS TRADIÇÕES JURÍDICAS COMMON LAW E CIVIL LAW: O PROBLEMA DA DISCRICIONARIEDADE.}

No final do século XX já se observava um movimento de maior aproximação entre o direito inglês e o direito do continente europeu, estimulada pelas necessidades do comércio internacional (DAVID, 1996, p. 301-302).

Para Daniel Mitidiero (2017, p. 25-26), enquanto, em suas origens, a tradição civil law buscava garantir a segurança jurídica através do legislador, a tradição common law, conforme analisado acima, pretendia garantir um sistema juridicamente seguro a partir da decisão judicial no âmbito do processo. Ocorre que, quando o direito inglês passa a ser concebido a partir da ideia de que o direito decorre da prática interpretativa, afasta-se, mesmo com a vinculação aos precedentes, a sensação de segurança jurídica havida, dada a complexidade do direito (MITIDIERO, 2017, p. 41).

O direito pertencente à família romano-germânica, segundo Cramer (2016, p. 31), tradicionalmente adotou os códigos como oráculos, com respostas prontas para todas as demandas da sociedade, sem espaço para interpretação. Ocorre que, do mesmo modo como ocorreu no direito inglês, o entendimento de que o juiz, ao fim, acabava por interpretar a lei, trouxe o problema da discricionariedade da atividade jurisdicional (MITIDIERO, 2017, p. 53). Houve, assim, nas duas tradições jurídicas, a busca pela estabilidade das normas e pela limitação do poder do julgador.

Porém, os dois sistemas jurídicos não atingiram o grau desejado de garantia da segurança jurídica e chegaram, ao fim, a um denominador comum, qual seja, a necessidade de criar uma teoria interpretativa que afastasse, desta atividade, a discricionariedade dos juízes. Neste sentido, é possível verificar que a tentativa de convergência das tradições jurídicas ocorre "para resolver, de maneira mais eficiente, os problemas práticos do sistema jurídico local, sem descaracterização da tradição originária” (CRAMER, 2016, p. 29).

Por essa razão, Peixoto (2019, p. 137) entende que a convergência não significa a mera importação de institutos estrangeiros, "mas de uma aprendizagem recíproca em busca de novas soluções que possam ser adaptadas ao ordenamento jurídico receptor e ressignificadas para que 
nele possam ser utilizadas". Além disso, para Cramer, além da necessidade de corrigir as deficiências de ambos os sistemas, a convergência se justificaria também pelos efeitos da globalização. Segundo o autor, "para garantir uma melhor circulação de negócios pelo mundo, a globalização reclama que os sistemas jurídicos dos países não sejam tão diferentes, que haja, assim, mais aspectos comuns do que distintos entre eles" (2016, p. 29-30).

Sob outro aspecto, nem mesmo a elevada produção normativa dos países de tradição romano-germânica foi suficiente para abranger os diversos fatos da vida cotidiana complexa, o que resultou na abertura de textos normativos, aptos, assim, a receber a atividade criativa dos julgadores (CRAMER, 2016, p.31).

Ainda, outro fator que influenciou a aproximação das duas tradições jurídicas foi o movimento do constitucionalismo (CRAMER, 2016, p. 32). Para Marinoni, partindo da concepção elementar de que a lei precisa estar adequada com os direitos fundamentais, "o juiz, mediante as técnicas da interpretação conforme a Constituição e da declaração parcial de nulidade sem redução de texto, confere à lei sentido distinto do que lhe deu o legislativo" (2011, p. 69). Assim, segundo o processualista, o julgador do civil law assemelha-se com a função criativa do juiz na tradição do common law (2011, p. 71).

Por fim, especificamente com relação ao precedente, sua aplicação, segundo Michelle Taruffo (2014, p. 01), é, também, uma realidade no civil law:

\begin{abstract}
Pesquisas realizadas em vários sistemas jurídicos têm mostrado que a referência ao precedente já não é mais, há algum tempo, uma característica peculiar aos ordenamentos de common Law, estando agora presente em quase todos os sistemas, mesmo nos de civil Law. [...] De um lado, de fato, nos sistemas de Civil Law faz-se amplo uso da referência à jurisprudência, enquanto nos sistemas de Common Law faz-se amplo uso da lei escrita e áreas inteiras desses ordenamentos - do direito comercial ao direito processual - são na realidade "codificadas".
\end{abstract}

O fato é que a convergência entre as tradições jurídicas em comento tem a jurisprudência como um alvo e um lugar de encontro, por meio da qual as tradições jurídicas foram se adaptando ao longo dos anos (MOTTA; RAMIRES, 2018, p.87). A partir disso, é preciso pontuar a recepção do precedente pelo Brasil e, especialmente, verificar se esse fenômeno apresenta uma racionalidade que venha a disciplinar a aplicação do precedente em perspectiva democrática. É o que se pretende realizar a seguir. 


\section{O PRECEDENTE NA TRADIÇÃO JURÍDICA BRASILEIRA}

Inicialmente, pela influência do direito português, o Brasil, ainda colônia de Portugal, experimentou a vinculação às decisões judiciais através dos assentos e apenas após a declaração da independência deixaram de ser utilizados no território brasileiro (CRAMER, 2016, p. 36). Segundo, é inquestionável que o Brasil esteja integrado à tradição jurídica do civil law, muito embora parte da doutrina aponte um modelo miscigenado (brasilian law) (PEIXOTO, 2019, p. 137). De qualquer forma, a história constitucional aponta para uma constante valorização da teoria dos precedentes, caminhando para a adoção de uma cultura do stare decisis (PEIXOTO, 2019, p. 137).

Em sua primeira Constituição Republicana, datada de 1891, o Brasil, por influência do direito constitucional norte-americano (ZANETI JR., 2019, p. 34-35), adotou o sistema de freios e contrapesos (ZANETI JR., 2019, p. 51), passando o Poder Judiciário “a exercer a função principal de mediador entre os poderes, por meio da judicial review" (ZANETI JR., 2019, p. 52). Para Zaneti Jr. (2019, p. 56), a Constituição republicana previa de maneira implícita o controle difuso de constitucionalidade, isso porque o artigo 59 possibilitava a interposição de recurso ao STF quando a decisão de última instância das Justiças dos Estados tivesse analisado matéria que tratasse, dentre outros casos, da validade de leis ou atos que levassem em consideração disposições constitucionais.

Já nesse período havia relatos doutrinários de que o STF teria reconhecido a possibilidade de o juiz Alcides de Mendonça Lima recusar a aplicação de "uma norma baixada por decreto do então Presidente do Rio Grande do Sul, Júlio de Castilhos, para disciplinar o júri de forma contrária ao estabelecido na Constituição" (ZANETI JR. 2019, p. 56). Entretanto, segundo Zaneti Jr (2019, p.56-57):

\footnotetext{
É importante frisar que o alcance dessa inconstitucionalidade era ainda muito limitado ao caso concreto, até mesmo porque no direito brasileiro não se tinha reconhecido, de imediato, a regra dos precedentes conhecida por stare decisis e, consequentemente, as decretações de inconstitucionalidade não tinham força vinculativa, atuando com mero alcance individual.
}

Na sequência histórica, a Constituição de 1934 previu a possibilidade de interposição de recurso extraordinário, de modo que se manteve o sistema de controle difuso de 
constitucionalidade. Segundo o artigo 76 daquela Constituição, o recurso extraordinário poderia ser interposto, perante a Corte Suprema, em face de decisão que, dentre outros motivos, tivesse analisado a validade de lei ou ato em face da Constituição (SARLET, MARINONI, MITIDIERO, 2017, n/p).

Por sua vez, o controle abstrato de constitucionalidade foi instituído apenas durante a vigência da Constituição de 1946, quando a Emenda Constitucional nº 16, de 26/11/1965, atribuiu ao STF a competência "para processar e julgar 'a representação contra inconstitucionalidade de lei ou ato de natureza normativa federal ou estadual, encaminhada pelo Procurador-Geral da República"” (SARLET, MARINONI, MITIDIERO, 2017, n/p). A Constituição de 1967 reforçou essa perspectiva.

Já a atual Constituição Federal de 1988, ao tratar do controle de constitucionalidade, manteve o controle difuso e ampliou o sistema de controle concentrado, com a ampliação do rol de legitimados a propor ação direta de inconstitucionalidade, e ainda com a possibilidade de ser apresentada arguição de descumprimento de preceito fundamental, bem como da ação declaratória de constitucionalidade, de acordo com a Emenda Constitucional n ${ }^{\text {o }}$ 03/1993 (CRAMER, 2016, p. 46-47).

A análise da história constitucional brasileira é importante porque esclarece, conforme mencionado por diversos autores (PEIXOTO, 2019, p. 137; ZANETI JR., 2019, p. 313), que a existência de uma aproximação entre a tradição do civil law e a do common law não é recente e está vinculada com o modelo adotado constitucionalmente pelo Brasil. Segundo Marinoni, há até mesmo incoerência da adoção do controle difuso de constitucionalidade em um país sem vinculação às decisões superiores, como ocorre no Brasil (2011, p. 74-75).

Desse modo, em um país com controle difuso de constitucionalidade, conforme destaca Zanetti Jr., "para que os tribunais cumpram sua função institucional de aplicar a constituição, é necessário adotar um sistema de precedentes através da regra do stare decisis (que inclui a vinculação argumentativa do próprio tribunal que exarou o precedente) (2019, p. 313).

A doutrina, como se observa, passou a destacar a necessidade da adoção de vinculação às decisões judiciais anteriores, a fim de evitar a insegurança jurídica trazida pela prolação de soluções diferentes para casos iguais. Cramer, por exemplo, menciona que "um sistema jurídico 
que tolera a não observância dos precedentes não apenas desinforma a sociedade do que é certo ou errado para o Direito, mas, principalmente, cria insegurança jurídica” (CRAMER, 2016, p. 55). Marinoni, a seu turno, entende que os precedentes seriam fundamentais "para outorgar segurança à parte e permitir ao advogado ter consciência de como os juízes estão preenchendo o conceito indeterminado e definindo a técnica processual adequada a certa situação" (MARINONI, 2011, p. 88).

Entretanto, é possível observar, a partir da década de 90, e sobretudo a partir da Emenda Constitucional 45, uma forte tendência reformista de índole neoliberal, fortemente impulsionada pela Nota Técnica 319 do Banco Mundial, ${ }^{7}$ direcionada justamente aos países da América Latina e do Caribe. A alta litigiosidade no país, com traços marcantes de demandas repetitivas, produtora de decisões distintas para casos similares, acabou cedendo à sedução das diretrizes do Banco Mundial, a fim de garantir uma imagem eficientista do sistema de justiça. Essa lógica que pautou as reformas processuais depois da EC 45/2004, focada na aceleração dos procedimentos, notadamente não estava voltada para amenizar as causas da alta litigiosidade. E, diante disso, o uso dos precedentes sinalizava para um êxito da expectativa de eficientismo (SANTOS, 2016, p.247-248).

Essa perspectiva de mercantilização da prestação jurisdicional pode ser inclusive observada na terminologia dos relatórios Justiça em Números do Conselho Nacional de Justiça, que passou a medir a produtividade dos juízes (STURZA; SANTOS, 2020) e, seguindo os auspícios da meritocracia, estabeleceu inclusive um ranking dos tribunais e premiou aqueles mais "produtivos". 8

Nesse cenário, a partir dos dois problemas gerados - o excesso legislativo e a soluções distintas para casos similares - "criou-se" um motivo para uma solução, que seria a adoção do precedente no Brasil, como se a common law preservasse um ideal ético de aplicação do direito, de natureza superior ao qual o sistema jurídico pátrio deveria se curvar (VIANA; NUNES,

\footnotetext{
${ }^{7}$ Ver em texto integral em DAKOLIAS, Maria. Banco Mundial: Documento técnico número 319. Disponível em: < https://www.anamatra.org.br/attachments/article/24400/00003439.pdf>, Acesso em: Maio.2020

${ }^{8} \mathrm{E}$ isso com o apoio significativo de campanhas políticas patrocinadas por grandes grupos econômicos e, de dentro, pelos próprios professores do ensino jurídico, cuja grande maioria se doutorou nos países dominadores (VIANA; NUNES, 2018, p.170-172).
} 
2018, p.97), sem olvidar do problema decorrente da litigiosidade galopante retratada especialmente por demandas de massa vulgarizadas e indesejáveis (SANTOS, 2016, p.147).

Esse bovarismo brasileiro, que Maria Rita Kehl apresenta como um comportamento ou concepção de um "si mesmo ideal” (2018, p.17), também é diagnosticado por Jessé Souza (2019 p.107), diante da cultura de opressão construída no Brasil a partir da especificidade de sua história, que minimiza o nacional e sobrevaloriza o que é diferente. Neste culto ao estrangeiro, o círculo de dominação se fecha quando a própria vítima do preconceito e do abandono social se culpa pelo destino que lhe foi preparado secularmente por seus algozes, introjetando no seio da sociedade uma moral diminuída e antiética que necessita do outro, do diferente, do estrangeiro, a fim de recuperar a sua eticidade.

Observa-se, assim, ao estilo bovarista, inicialmente uma extremada valoração do precedente no Brasil, sem a formação prévia de uma racionalidade adequada, sobretudo em aspectos constitucionais, tornando esse instituto a solução de todos os nossos problemas no âmbito da teoria da decisão judicial (SANTOS, 2016, p.113), pois (SANTOS, 2016, p.150-151)

\begin{abstract}
A partir das reformas processuais operadas na última década, subjaz, portanto, na cultura jurídica brasileira, a construção de um procedimentalismo de caráter universal e abstrativista, quando procura dar, aos chamados conflitos repetitivos, o mesmo tratamento previsto para os conflitos de cariz claramente individualista. E na via da adequação, com a peculiaridade brasileira, criam-se julgamentos por amostragem e, para sustentá-lo, uma indesejada jurisdição conceitual, que aposta na vulgarização da análise do caso concreto para superficializar a decisão judicial, a pretexto de criar uma jurisdição célere onipotente, eis que conceitual e abstrata.
\end{abstract}

O alerta também procede de Rodolfo Mancuso (2018, p.282), para quem é preciso estarmos atentos a este pragmatismo exacerbado, voltado para uma performance quantitativa e para uma obsessiva aceleração dos processos.

Mas, para além dos extremos e, considerando ser devida a harmonização das decisões judiciais, é preciso compreender a racionalidade que disciplina a busca de padrões argumentativos, harmonizada com os preceitos constitucionais, sobretudo a partir do princípio da isonomia, que, sob uma perspectiva democrática, garante o tratamento igualitário do cidadão em situação conflituosa semelhante. Mas como de fato está estruturada essa lógica argumentativa no Brasil? É o que se pretende analisar no item a seguir. 


\subsection{Há um "sistema" de precedentes no Brasil?}

É nesse cenário que surge o Código de Processo Civil de 2015, apresentando "um sistema vocacionado ao extremo respeito às decisões anteriores, adote-se ou não a nomenclatura do precedente judicial" (VIANA, NUNES, 2018, p. 196), direcionado, ainda, segundo Peixoto, para consolidar as reformas anteriores para tentar instaurar o stare decisis no direito brasileiro (2019, p. 138).

Quando da aprovação do Projeto do Código de Processo Civil pela Câmara dos Deputados, houve a menção, no relatório do Deputado Paulo Teixeira, a um sistema de precedentes adotado no Projeto. Ainda, para Vieira e Nunes, partindo do conceito de sistema, é imperativo concluir que as disposições previstas no CPC de 2015 sobre a vinculação aos precedentes podem ser entendidas como um sistema (VIANA, NUNES, 2018, p. 201). Isso porque os precedentes estão dispostos no Código de modo a criar "um elo, um encadeamento das técnicas favoráveis à aplicação dos precedentes" (VIANA, NUNES, 2018, p. 202).

Se os precedentes são necessários para evitar a prolação de decisões diferentes para casos iguais (CRAMER, 2016, p. 55), para Francisco Motta e Maurício Ramires a invocação dos precedentes como fundamentação da decisão judicial é apenas um capítulo desta história (MOTA; RAMIRES, p.87-88). Dito de outra forma, "pouco ou quase nada se ganha em termos de democracia, se uniformizarmos decisões a partir de julgados discricionários, tão somente porque provenientes dos Tribunais” (NERY JR/ABBOUD, 2013).

É preciso, pois, definir qual racionalidade, no âmbito da nossa cultura jurídica, sustenta essa perspectiva, a iniciar pelo microssistema do Código de Processo Civil de 2015.

\subsection{O microssistema composto pelos artigos 926, 927 e 928 do CPC}

Dentre as disposições do CPC de 2015 que tratam sobre a utilização dos precedentes é possível destacar um microssistema constituído pelos artigos 926, 927 e 928, que determina, 
em síntese, a manutenção de uma jurisprudência estável, íntegra e coerente, em respeito às decisões judiciais proferidas pelos tribunais. ${ }^{9}$

Segundo Cramer (2016, p. 183-187), existem cinco possíveis correntes que, de forma distinta, interpretam as diretrizes do art.927 do CPC. A primeira defende que há, de fato, um rol de precedentes vinculantes no art.927. A segunda corrente entende que não há vinculação nas hipóteses previstas no referido artigo, pois a vinculação estaria relacionada à previsão da reclamação constitucional. A terceira compreende que o art. 927 não atribui força vinculante aos precedentes ali listados, mas exige que tais precedentes sejam "considerados" nas decisões judiciais (CRAMER, 2016, p. 185). A quarta corrente preleciona que, se o rol previsto no artigo 927 fosse vinculante, o artigo seria inconstitucional. Por fim, a quinta corrente defende que apenas os tribunais superiores teriam a possibilidade de criar precedentes e que estes, independentemente de previsão legal, seriam vinculantes.

Para Daniel Mitidiero, os arts.926 e 927 tornam mais visível o stare decisis no Brasil (MITIDIERO, 2017, p.82). Contudo, como bem leciona Georges Abboud e Marcos Cavalcanti, enquanto o stare decisis aposta no caso concreto e na qualidade, o novo CPC vai na linha do julgamento em teses abstratas e na quantidade (ABBOUD/CAVALCANTI, 2015).

Muito embora seja controverso o olhar sobre o teor do art.927 do CPC, não há controvérsia acerca da existência, no novo CPC, de uma proposta de precedentes ou padrões decisórios, que representa, segundo Vieira e Nunes, um iter mínimo que deve ser observado sob a lente constitucional, seguindo os princípios constitucionais processuais a partir do devido processo legal. Segundo os doutrinadores (VIANA; NUNES, 2018, p. 295),

ao pretenderem instituir um sistema de precedentes supostamente capaz de assegurar isonomia, segurança jurídica, celeridade e felicidade ao jurisdicionado, negligenciam a ausência de fechamento argumentativo que marca o uso do direito jurisprudencial nos países da tradição do common law, tendo em vista a impossibilidade de, lá, o precedente ser anunciado de forma completa e única, inaugurando-se na retaguarda da decisão anterior, a própria problematização quanto à sua aplicação.

\footnotetext{
${ }^{9}$ Em outros espaços do Código, a exemplo do art.332, impõe-se o julgamento liminar do pedido quando a tese aplicada for aquela definida por algum dos precedentes relacionados no dispositivo, reproduzindo o que, nesse sentido, já impunha o antigo art. 285-A, introduzido pela Lei 11.277/2006 no CPC de 1973. Destaca-se o art.489, no $\S 1^{\circ}$, inciso $\mathrm{V}$, que nega a devida fundamentação da sentença se o juiz, ao aplicar um precedente, não demonstrar quais são os fundamentos determinantes deste e porque o caso se encaixa nesses fundamentos. Além disso, o inciso VI do mesmo dispositivo estabelece a necessidade de que o juiz, ao deixar de seguir um precedente, demonstre a distinção com o caso concreto ou a superação do entendimento.
} 


\subsection{Jurisprudência, súmula e precedente}

Uma vez definida a existência no ordenamento jurídico de um sistema de precedentes, é importante compreender os três institutos mencionados no CPC e que com frequência são mal compreendidos: jurisprudência, o enunciado de súmula e o precedente.

Inicialmente, é árdua a tarefa de identificar um precedente. Conforme preleciona Taruffo (2014, p. 03), nas famílias que pertencem à tradição jurídica do civil law, devido à inúmera profusão de decisões judiciais sobre um mesmo assunto, torna-se difícil estabelecer qual foi a decisão que inaugurou a aplicação de um entendimento (precedente).

Cramer (2016, p. 202) menciona que, no Brasil, antes das disposições trazidas pelo Código de Processo Civil de 2015, "não se utilizava o precedente, mas sim a jurisprudência como reforço de discurso jurídico" (CRAMER, 2016, p. 202). Conforme mencionado anteriormente, não havia critério para a aplicação da jurisprudência: "tudo era jurisprudência, conforme o interesse do interlocutor" (CRAMER, 2016, p. 202). Além disso, citavam-se as jurisprudências apenas considerando as ementas dos seus julgados, sem nenhuma referência aos seus fundamentos (CRAMER, 2016, p. 202).

Assim, além da falta de técnica para definir a existência de um precedente, percebe-se a utilização de equivocada técnica interpretativa, que trata o precedente como se texto normativo fosse. Esse modo de interpretar os julgados é, segundo Cramer (2016, p.82), consequência da cultura do civil law:

\footnotetext{
No sistema de precedentes, a súmula não deve ser aplicada de forma autônoma em relação ao precedente originário, como se ela mesma fosse o precedente ou, ainda, um texto normativo. É isso o que se tem feito até hoje, seja na teoria, seja na prática. Pegase o texto da súmula e se faz a sua interpretação e aplicação de forma indiferente ao precedente originário. Esse uso incorreto da súmula decorre do nosso costume, próprio da tradição do Civil Law, de fazer a subsunção entre a norma do dispositivo legal e o fato gerador. Crê-se que a tese jurídica está retratada no texto da súmula e, por isso, se promove apenas a sua interpretação e aplicação ao caso concreto. Não se tem o hábito de ir ao precedente, para identificar a tese jurídica e aplicá-la ao caso concreto.
}

Assim, "chama-se de precedente o que de fato não é, como se dá nos casos de invocação da de súmula, atribuindo a esta as características de abstração e generalização reservadas à lei”" (VIANA, NUNES, 2018, p. 54). 
Ocorre que a norma produzida pelo precedente "se encontra no texto do precedente, e esse texto necessita ser interpretado para que dele seja depreendida" (CRAMER, 2016, p. 89). Entretanto, essa interpretação não pode se dar da mesma forma que se faz com lei. Isso porque, conforme já mencionado, a lei possui conceitos gerais e abstratos (STRECK, ABBOUD, 2013, p. 31), trazendo, em várias situações, a necessidade de o juiz exercer uma função criativa do direito, a fim de que a norma consiga ser aplicada ao caso concreto.

No precedente, por sua vez, o que se tem é um exemplo a ser seguido em casos que tratem sobre idêntica questão de direito (STRECK, ABBOUD, 2013, p. 63), ou seja, casos em que não seja necessário que os juízes se utilizem dessa função criativa do direito para moldar o texto normativo do precedente ao caso analisado.

Desse modo, quando se entende, como acontece no Brasil, que a regra do precedente vira um novo texto normativo - geral e abstrato -, este passa a ser interpretado como se lei fosse, o que gera a necessidade de moldar, ainda mais, o texto normativo ao caso concreto, afastando-se sobremaneira o posicionamento jurisprudencial da previsão legal que originou o entendimento fixado pelo precedente.

Não há como negar que tal método de interpretação dos precedentes implica insegurança jurídica: a cada aplicação do precedente (ou jurisprudência) - que já não é facilmente definido (TARUFFO, 2014, p. 03) -, é feita uma nova interpretação, que pode, ou não, chegar ao direito essencialmente aplicado no precedente. E, para Viana e Nunes (2018, p.06),

\footnotetext{
Todos esses aspectos, somados a uma tendência de julgamento de teses cada vez mais desligado do caso, quase como se ele fosse somente um pretexto para o delineamento de análises nas quais em tese se possam desprezar as peculiaridades e as individualidades dos conflitos em análise, tornam ainda mais complexa a absorção de precedentes normativos em nosso país, especialmente quando se percebe que a racionalidade de seu uso no estrangeiro dificilmente se afasta dos fatos operativos para que se promovam as analogias, ou contra-analogias entre o precedente e a atual situação de julgamento.
}

Por fim, cabe a lição de Streck e Abboud, para quem precedentes são formados para resolver casos concretos e eventualmente influenciam decisões futuras, enquanto súmulas, ao contrário, são enunciados "gerais e abstratos" - características presentes na lei - que são editados visando à "solução de casos futuros" (STRECK, ABBOUD, 2013, p. 30-31). 
Portanto, cabe dizer o que o precedente não é: jurisprudência, decisão judicial, súmula, ementa ou enunciado. Por fim, de acordo com Zaneti Jr. (2019, p. 329),

não será precedente, a decisão que simplesmente aplicar um caso-precedente já existente, ou a decisão que não tiver conteúdo de enunciação de uma regra jurídica ou de um princípio universalizável. Assim como, não será precedente, a decisão que apenas se limitar a indicar a subsunção de fatos ao texto legal, sem apresentar conteúdo interpretativo relevante para o caso-atual e para os casos-futuros.

\section{O SISTEMA DE PRECEDENTES NO BRASIL: QUAL RACIONALIDADE?}

Inicialmente, foi possível observar no presente estudo que a tradição jurídica do common law, antes da utilização de um precedente, realiza uma rigorosa análise por meio da qual se verifica se existe precedente sobre o assunto, qual é o caso que gerou esse precedente, qual foi a norma por ele criada e, ainda, se o caso que está sendo julgado se identifica com o caso que gerou o precedente (VIANA, NUNES, 2018, p. 374-375).

No Brasil, quando são invocadas outras decisões como razão de decidir, esta atividade é feita sem nenhum critério, o que muitas vezes acaba por contrariar a própria decisão que gerou o precedente (CRAMER, 2016, p. 05; PEIXOTO, 2019, p. 140, VIANA, NUNES, 2018, p. 09).

Desse modo, como resultado da ausência de uma técnica de aplicação das decisões judiciais, não são raros, no Brasil, “os casos em que a jurisprudência não é respeitada, ou modificada meses depois de formada, ou forjada a partir de obter dictum, isto é, com base em argumentos que não integram as razões de decidir" (CRAMER, 2016, p. 05).

Pelo exposto, e considerando que o Código de Processo Civil apresentou uma proposta de aplicação dos precedentes, é preciso atentar para o fato de que a "obrigatoriedade da vinculação de precedentes sem o seu adequado tratamento apenas sinaliza para o pior dos cenários possíveis: uma vinculação de precedentes com a contínua ignorância das circunstâncias fáticas necessárias para a interpretação dos precedentes” (PEIXOTO, 2019, p. 140). 
A partir disso, é possível apontar uma racionalidade adequada de aplicação dos precedentes a partir do CPC de 2015 ?

No art.926 do CPC de 2015 foram incluídos os critérios da coerência e da integridade para preservar a uniformização e estabilidade da jurisprudência. Tais critérios decorrem da filosofia de Ronald Dworkin e sua inserção no projeto de lei do novo código foi resultado de proposição de emenda ao Anteprojeto por Lênio Luiz Streck. Na concepção de Dworkin (2003, p.272), o direito como integridade é essencialmente interpretativo, razão pela qual a decisão não pode ser compreendida como um ato de criação, mas sim produto de um processo ininterrupto de desenvolvimento e identificação dos direitos no contexto de uma comunidade personificada e em conformação com ela, bem como mantendo a devida coerência com os preceitos de justiça e do devido processo legal. Sob este viés, o dever de um juiz é interpretar a história jurídica que encontra, e não de inventar uma história melhor (DWORKIN, 2005, p.240).

Para Motta e Ramires (2018, p.95), a integridade é compreendida "como a necessidade de que o governo tenha uma só voz aja de modo coerente e fundamentado em princípios com todos os seus cidadãos”. Em outras palavras, todos devem receber os mesmos padrões fundamentais de justiça e equidade, ou ainda, o Estado deve tratar a todos com igual respeito e consideração, como uma virtude política, uma exigência específica de sua moralidade política.

Nessa mesma linha, para Viana e Nunes (2018, p.411-412), integridade é um "empreendimento conjunto" para o tratamento do sistema normativo, por parte dos juízes, como se esse sistema "expressasse e respeitasse um conjunto coerente de princípios, atendendo a uma lógica de continuidade". Ainda, reforçam os autores que o juiz deve interpretar "o que os juízes do passado escreveram (decidiram) coletivamente e, na sequência, acrescentar a sua própria decisão à história institucional".

Já por coerência, embora coerência e integridade devam ser compreendidas em conjunto, os termos não se confundem (Viana e Nunes, p.406). Mais do que mera consistência lógica frente a casos semelhantes, a coerência do julgado precisa expressar uma visão única e compreensível de justiça. Isso significa que, muito embora o julgamento atual deva considerar os julgados semelhantes do passado, estes também precisam sem valorados ou adaptados em caso de ter ocorrido eventual equívoco. Isso é casuística e respeito à problemática do Direito, para assim usar a expressão do mestre Ovídio Baptista da Silva. 
Assim, observa-se que os critérios de coerência e integridade oferecem elementos para a definição de uma racionalidade adequada para aplicação dos precedentes. Tais critérios são ainda reforçados por outras diretrizes presentes no novo Código, constantes no parágrafo $2^{\circ}$ do mesmo dispositivo legal, que determina que "ao editar enunciados de súmula, os tribunais devem ater-se às circunstâncias fáticas dos precedentes que motivaram sua criação". Ainda, também o artigo 489 prevê, nos incisos V e VI do seu parágrafo $1^{\circ}$, balizas que sinalizam para a criação de uma racionalidade de aplicação dos precedentes. Aliás, foi necessário dizer que, por ocasião da fundamentação da decisão judicial, não será aceita a mera subsunção do precedente ou súmula. O julgador terá de cotejar os elementos de conexão ou de distinção entre a casuística sob análise e normativo a ser invocado ou afastado para sustentar sua decisão.

Observa-se, assim, a vertente propositiva do novo $\mathrm{CPC}$, que permite a criação de uma cultura jurídica com maior capacidade de argumentação e, com ela, um maior compromisso com a casuística sob julgamento.

Sob o ponto de vista do advogado, haverá a necessidade de realização de um trabalho técnico de comparação de casos, a fim de que buscar a aplicação ou o afastamento das normas (VIANA, NUNES, 2018, p. 05). O resultado desse trabalho é a construção de uma argumentação que igualmente irá provocar e enriquecer o trabalho do julgador.

Por outro lado, alertam Viana e Nunes (2018, p. 20) que "a ignorância de como julgam os casos (qual é a história institucional), sem dúvidas, é um fator decisivo para a anarquia interpretativa, que induz dispersão e a litigância sem fundamentação adequada", de modo que a previsão do art.927, parágrafo $5^{\circ}$ do CPC, que determina a ampla publicidade dos precedentes, é fundamental para que todo esse trabalho possa ser realizado.

No Brasil, desde 2018 a Escola Nacional de Formação e Aperfeiçoamento de Magistrados, em parceria com o STJ, disponibiliza um banco de dados por meio da ferramenta Corpus927, que concentra todas as decisões vinculantes, enunciados e jurisprudências das cortes superiores. Atualmente, além do acesso direito na plataforma Corpus927, desde o final de junho de 2020 a própria página do planalto.gov libera o acesso aos dados por meio de um 
ícone (martelinho), que fica ao lado de cada artigo do CPC, por exemplo (BRASIL, ENFAM, 2020). ${ }^{10}$ Como se observa, uma organização bastante recente e ainda muito incipiente.

Tal solução seria o que se poderia chamar de uma versão brasileira dos Year Books compilado de sentenças, que foram utilizados no direito inglês entre 1290 e 1536 (DAVID, 1996, p. 299), e "contribuíram para que, aos poucos, o common law fosse aplicado de modo mais natural” (VIANA, NUNES, 2018, p. 46-47) -; ou, então, a versão brasileira dos Law Reports, que são as compilações de julgados do direito inglês, que substituíram os Year Books, sendo utilizados até os dias atuais (DAVID, 1996, p. 299, 344-345) como referência à aplicação dos precedentes.

De todo modo, na linha do que preconizam Aurélio Viana e Dierle Nunes (2018, p.295), o desafio trazido pelo novo CPC consiste na obviedade, que ainda deve ser dita, no sentido de que os fundamentos normativos para um pretenso sistema brasileiro de precedentes requer necessariamente uma leitura constitucional do direito jurisprudencial, isso porque está em vigor uma estrutura constitucional de proteção de elementos fundantes (cidadania) e direitos fundamentais (acesso à justiça, devido processo legal) conquistados duramente após um longo período de repressão e opressão. A Constituição, portanto, é o critério da racionalidade aqui buscado.

Qualquer discurso que pretenda desvirtuar essa máxima já nasce vicioso e não pode ser aceito pela comunidade jurídica. Por isso, é preciso acrescentar mais um elemento nessa reflexão, o qual necessariamente perpassa pela formação acadêmica e por qual ética o sistema de justiça espera de seus profissionais. É o que se pretende abordar a seguir.

\section{O IMPORTANTE PAPEL DA EDUCAÇÃO JURÍDICA}

A tendência brasileira de não dar a devida importância à aplicação do precedente fez com que o tema inclusive não fosse devidamente desenvolvido no ambiente acadêmico

\footnotetext{
${ }^{10} \mathrm{O}$ banco de dados está disponível para consulta das decisões consolidadas em < http://corpus927.enfam.jus.br/> Acesso em: 03Jul2020.
} 
(VIANA, NUNES, 2018, p. 181), o que sem dúvida dificulta o processo de adaptação da teoria dos precedentes.

O mundo se transforma, os conflitos se ampliam e se recriam. Os sistemas de justiça igualmente precisam se adaptar. Não é possível tratar conflitos da contemporaneidade com os mesmos e velhos conceitos dos séculos passados. A concepção gadameriana de tradição provoca justamente a constante e circular compreensão do intérprete a partir da sua consciência histórica e interpelação de suas antecipações prévias (GADAMER, 2006, p.69).

Outra não era a preocupação do mestre Ovídio Baptista da Silva, ao denunciar o geometrização do Direito e o anacronismo do ensino universitário no Brasil, que sonega do aluno a essencial dimensão problemática do Direito, fazendo com que apenas o longo tempo de prática profissional irá desfazer as ilusões da Universidade (SILVA, 2006, p.36-38).

Nessa linha, a conexão com a realidade e a adaptação do ensino jurídico, para além dos códigos, é fundamental para superar as distorções que podem atrapalhar a atuação do futuro profissional no âmbito do sistema de justiça. Além disso, a humanização do ensino jurídico é fundamental sob o ponto de vista do acesso à justiça, sobretudo para que, em cada atuação deste novo perfil de profissional, esteja o reflexo da defesa da democracia e seus pilares mais caros, quais sejam os direitos e garantias fundamentais do cidadão, dentre os quais se encontra o devido processo legal.

Desse modo, a última e não menos importante mudança a ser citada, no âmbito cultural das tradições jurídicas, diz respeito à formação jurídica dos operadores de direito (CRAMER, 2016, p. 205).

Veja-se que a transformação cultural aqui decorre da reforma legislativa. Nessa perspectiva, Oscar Chase defende que o modo como os conflitos são solucionados, o que ele chama de instituições de resolução de conflitos, são, concomitantemente, produto, colaboração e aspecto da cultura (Chase, 2014, p.27), pois suas práticas são instrumentos sinalizadores de valores, crenças e papeis sociais (Chase, 2014, p.30). Ou seja, a forma como determinada cultura resolve seus conflitos, seus rituais e mecanismos, tanto refletem como também constituem essa mesma cultura (Chase, 2014, p.34). 
Nessa linha de raciocínio, é possível compreender a lógica instaurada pelo novo CPC e sua legitimidade enquanto proposta de adaptação da cultura jurídica brasileira, seguidora da tradição civil law, a fim de que seu sistema de justiça se renove e, diante da nova realidade conflituosa, adapte seus rituais de resolução de conflito, respeitando notadamente os direitos e garantias fundamentais.

Para tanto, faz parte dessa perspectiva a busca de uma formação jurídica compatível com os novos rituais. $\mathrm{O}$ ensino jurídico, neste sentido, precisa estar apto a preparar profissionais que sejam capazes de, não só se adaptarem e esse novo sistema de justiça, mas sobretudo que tenham capacidade de percepção (expertise) das circunstâncias do caso concreto, para então dar a ele o devido tratamento, com suas idiossincrasias.

$\mathrm{Na}$ linha do que observam Viana e Nunes, "boa parte dos advogados inseridos na tradição do civil law - e, por certo, no Brasil também é assim - não domina as técnicas de aplicação de precedentes judiciais" (VIANA, NUNES, 2018, p. 239), o que pode levar a uma estagnação na aplicação dos dispositivos previstos no CPC/2015 (VIANA, NUNES, 2018, p. 239).

A fim de mudar esse cenário, deverá o ensino jurídico começar a tratar de conceitos essenciais à utilização de precedentes, a fim de que ao menos os futuros profissionais consigam visualizar o sistema de precedentes de maneira mais correta (CRAMER, 2016, p. 206). No dizer de Peixoto, "não fez parte da formação dos magistrados a aceitação de que deveria haver uma mitigação de sua liberdade interpretativa a partir das decisões dos tribunais superiores [...]"(2019, p. 141).

É claro que as dificuldades de aplicação dos precedentes não ocorrem exclusivamente em razão da formação jurídica dos sujeitos processuais imbricados no tratamento de conflitos, mas notadamente o desconhecimento e a ausência de uma racionalidade adequada é um obstáculo às transformações que o sistema de justiça precisa realizar para se adaptar aos conflitos na contemporaneidade.

Algumas ações devem ser realizadas para superar esse obstáculo. Uma delas é a readequação dos currículos do ensino jurídico, que devem incluir o conteúdo sobre precedentes 
de maneira sistêmica, ou seja, não apenas na disciplina de Processo Civil (Cramer, 2016, p. 206).

Mas para além da proposta conteudista, é preciso também e sobretudo abordar essa transformação no âmbito do acesso à justiça. Kim Economides, na perspectiva de Mauro Cappeletti, observa a importância de tratar de uma quarta onda renovatória de acesso à justiça, que estaria relacionada à capacidade que os operadores do direito possuem de garantir aos cidadãos o acesso à justiça (ECONOMIDES, 1999, p. 71-73).

Nesse sentido, a quarta onda "expõe as dimensões ética e política da administração da justiça e, assim, indica importantes e novos desafios tanto para a responsabilidade profissional como para o ensino jurídico" (ECONOMIDES, 1999, p. 72). Desse modo, Economides destaca que "é necessário entender melhor o papel e as responsabilidades das faculdades de direito na formação do caráter profissional dos advogados" (1999, p. 74), sendo essencial que se debatam os meios pelos quais poderão os futuros juízes e os advogados não apenas participar do processo jurisdicional - buscando atingir o fim de um processo -, mas também perseguir a correta aplicação do direito, o que é, por Economides, denominado de justiça, e que é, ao fim e ao cabo, a razão de ser do Direito.

A pesquisa acerca do acesso à justiça em âmbito global foi renovada em 2018 por meio do Global Access to Justice Project (HENRICHS, 2020, p.3). O projeto Florença não contou com a participação do Brasil, mas o novo projeto global é justamente uma iniciativa de Diogo Esteves e Cleber Francisco Alves (HENRICHS, 2020, p.3), defensores públicos e pesquisadores brasileiros. ${ }^{11}$ Na nova pesquisa global, de maior amplitude, a ética das profissões a partir da educação jurídica está na perspectiva da quarta onda de acesso à justiça, o que revela a influência e o impacto da atuação e da prática das profissões jurídicas sobre a efetivação do acesso à justiça na contemporaneidade. ${ }^{12}$

É interessante notar que, em meio à dinâmica das mudanças sociais, acelerada pela tecnologia em um mundo globalizado, a educação jurídica ainda seja, ao final, motivo de grande

\footnotetext{
${ }^{11}$ Ver em "Perspectivas acerca do Global Access to Justice Project", Aula Aberta proferida pelo Prof.Dr.Claber Francisco Alves para o PPGD/UFPEL, em 30 de Outubro de 2020. Disponível em: <https://www.youtube.com/watch?v=eCu7vG6TjuQ\&t=3768s>.

12 Ver "Panorama do Livro" no Meu no site do Global Access to justice. Disponível em: <http://globalaccesstojustice.com/book-outline/?lang=pt-br>, Acesso em: 30.Jun.2020.
} 
atenção para uma vida social e profissional atenta à defesa da dignidade humana. Mas certamente isso já é assunto para outro trabalho, notadamente interminável.

\section{CONSIDERAÇÕES FINAIS}

A doutrina brasileira se posiciona de forma a recepcionar um sistema de precedentes que confira segurança jurídica no âmbito das decisões judiciais. Nesse contexto, o que deve ser destacado é que os fundamentos normativos para um pretenso sistema brasileiro de precedentes requerem necessariamente uma leitura constitucional do direito jurisprudencial, pois, muito antes de se cogitar um sistema de precedentes, impõe-se uma estrutura constitucional de proteção de elementos fundantes (cidadania) e direitos fundamentais (acesso à justiça, devido processo legal) conquistados duramente após um longo período de repressão e opressão. A Constituição, portanto, é o critério da racionalidade aqui buscado para admitir uma estrutura e aplicabilidade de precedentes no Brasil.

Nessa perspectiva, a estrutura buscada para parametrizar decisões com coerência de integridade, a fim de garantir segurança jurídica, não pode ser sobreposta por uma lógica eficientista de redução da litigância excessiva e da superficialização ou abstrativização dos julgamentos.

Também restou destacado que, partindo da premissa de que o acesso à justiça é o mais elementar direito humano, a mera proclamação de direitos de nada serve se não houver um sistema de justiça constitucionalmente adequado para que tais direitos possam ser legitimamente reivindicados. Nesta perspectiva, a recepção do sistema de precedentes, fortalecida pela chegada do novo CPC em 2015, deve adequar-se aos preceitos constitucionais que orbitam em torno do devido processo legal e, com isso, à efetividade dos direitos fundamentais.

Para que na prática essa adequação se materialize, impõe-se um ensino jurídico compatível com a nova realidade de conflitos e que proporcione aos futuros profissionais a aptidão para conformar e conduzir o tratamento de conflitos sociais em respeito à tradição 
constitucional, pois a compreensão e a interpretação são fenômenos particularmente realizados e interpelados pela tradição, levando em consideração seus elementos temporais e históricos, o que revela a importância da construção de uma racionalidade adaptada à cultura jurídica brasileira. A mera importação de institutos estrangeiros, supostamente mais éticos e legítimos, além de não resolver os problemas que obstaculizam a efetividade dos direitos, revela-se como um menosprezo às particularidades da cultura e história do direito brasileiro.

Assim, a construção de uma racionalidade de aplicação dos precedentes constitucionalmente adequada requer não só o respeito à tradição constitucional brasileira, como também a perspectiva de um ensino jurídico que realmente assegure a ética profissional necessária para contribuir com a efetividade dos direitos no âmbito do acesso à justiça.

Afinal, a busca da segurança jurídica deve ser um reflexo natural de comprometimento de todos os sujeitos envolvidos nessa transformação. Antes da segurança jurídica, é a defesa da democracia e seus pilares que devem motivar o movimento e o posicionamento de um sistema de justiça, para além das importações messiânicas, em respeito à nossa própria identidade e dignidade.

\section{REFERÊNCIAS BIBLIOGRÁFICAS}

BODNAR, Zenildo; CRUZ, Paulo Márcio. A commolização do direito positivo, o ativismo judicial e a crise do Estado. Revista Novos Estudos Jurídicos, v. 21, n. 3, p. 1332-1351, set./dez. 2016. DOI: 10.14210/nej.v21n2.p1332-1351. Disponível em: <https://siaiap32.univali.br/seer/index.php/nej/issue/view/398>. Acesso em: 27 set. 2019.

BRASIL. Lei $\mathrm{n}^{\circ}$ 13.105, de 16 de março de 2015. Código de Processo Civil. Brasília: Presidência da República, 2015.2 Disponível em: <http://www.planalto.gov.br/ccivil_03/_ato2015-2018/2015/lei/113105.htm>. Acesso em: 27 de set. 2019.

BRASIL, ENFAM. Novo sistema de pesquisa de jurisprudência é lançado. Disponível em: <https://www.enfam.jus.br/2018/06/novo-sistema-de-pesquisa-de-jurisprudencia-e-lancado/>. Acesso em:03Jul.2020.

CARDOZO, Benjamin N. A natureza do processo judicial. São Paulo: Martins Fontes, 2004.

CAPPELLETTI, Mauro; GARTH, Bryant. Acesso à Justiça. Tradução e revisão: Ellen Gracie Northfleet. Porto Alegre: Fabris, 1988. 
CHASE, Oscar G. Direito, Cultura e Ritual: sistemas de Resolução de conflitos no contexto da cultura comparada. $1^{a}$ Edição. Tradução de Sérgio Arenhart, Gustavo Osna. São Paulo: Marcial Pons, 2014.

CRAMER, Ronaldo. Precedentes judiciais: teoria e dinâmica. 1. ed. Rio de Janeiro: Forense, 2016.

DAVID, René. Os grandes sistemas do direito contemporâneo. 3. ed. São Paulo: Martins Fontes, 1996.

DAKOLIAS, Maria. Banco Mundial: Documento técnico número 319. Disponível em: < https://www.anamatra.org.br/attachments/article/24400/00003439.pdf>, Acesso em: Maio.2020

DWORKIN, Ronald. O Império do Direito. São Paulo: Martins Fontes, 2003.

DWORKIN, Ronald. Uma questão de princípio. São Paulo: Martins Fontes, 2005.

ECONOMIDES, Kim. Lendo as ondas do "Movimento de Acesso à Justiça": epistemologia versus metodologia? In: PANDOLFI, Dulce Chaves; CARVALHO, José Murilo de; CARNEIRO, Leandro Piquet; GRYNSZPAN, Mario (org). Cidadania, justiça e violência. Rio de Janeiro: Ed. Fundação Getúlio Vargas, 1999. Disponível em: <https://bibliotecadigital.fgv.br/dspace/bitstream/handle/10438/6742/39.pdf.>.Acesso em: 27 set. 2019.

GADAMER, Hans-Georg. O problema da consciência histórica. Rio de Janeiro: FGV, 2006.

GARTH, Braynt [et al].Global Access to justice Justice Project. Disponível em: <http://globalaccesstojustice.com/book-outline/?lang=pt-br>, Acesso em: 30.Jun.2020.

HENRICHS, Cristiane Maria. New Global Access to Justice Project: consolidação de ideias antigas - reflexão sobre as novas ideias. Revista Eletrônica da OABRJ. Edição Especial da Comissão de Mediação de Conflitos. Ano 1, n. 1. Janeiro/Junho 2020, p.1-31.

Disponível em: < https://revistaeletronica.oabrj.org.br/wp-content/uploads/2020/07/NEWGLOBAL-ACCESS-TO-JUSTICE-PROJECT-Cristiane-henrichs-3.pdf> Acesso em: 22Mar2021.

KEHL, Maria Rita. Bovarismo brasileiro. São Paulo: Boitempo, 2018.

MARINONI, Luiz Guilherme. Precedentes obrigatórios. 2. ed. rev. e atual. São Paulo: Editora Revista dos Tribunais, 2011.

MAUS, Ingeborg. O Judiciário como superego da sociedade: o papel da atividade jurisprudencial na "sociedade órfã". Novos estudos CEGRAP, São Paulo, n. 58, p. 183-202, nov. 2000.

MITIDIERO, Daniel. Precedentes: da persuasão à vinculação. 2. ed. São Paulo: Editora Revista dos Tribunais, 2017. 
MANCUSO, Rodolfo de Camargo. Acesso à Justiça. Condicionantes legítimas e ilegítimas. Salvador: Juspodivm, 2019.

MORAES, Alexandre de. Direito constitucional. 33. ed. rev. e atual. São Paulo: Atlas, 2017.

MOTTA, Francisco José Borges; RAMIRES, Maurício. O novo Código de Processo Civil e a decisão jurídica democrática: como e por que aplicar precedentes com coerência e integridade? In: Hermenêutica e Jurisprudência no Código de Processo Civil - Coerência e Integridade. São Paulo: Saraiva, 2018, pp.86-112.

NERY JUNIOR, Nelson. ABBOUD, Georges. Stare Decisis vs Direito Jurisprudencial. In: FREIRE, Alexandre [et al]. Novas Tendências do Processo Civil: Estudos Sobre o Projeto de Novo Código de Processo Civil. Bahia: Editora JusPodivm, 2013, p. 483-512.

PEIXOTO, Ravi. Superação do precedente e segurança jurídica. 4. ed. rev., ampl. e atual. Salvador: Editora JusPodivm, 2019.

SANTOS, Karinne Emanoela Goettems dos. Processo Civil e Litigiosidade. Rio de Janeiro: Lumen Juris, 2016.

SARLET, Ingo Wolfgang; MARINONI, Luiz Guilherme; MITIDIERO, Daniel. Curso de direito constitucional. 6. ed. São Paulo: Saraiva, 2017.

SILVA, Ovídio Baptista da. Processo e Ideologia: o paradigma racionalista. Rio de Janeiro: Forense, 2006.

SOUZA, Jessé. A elite do atraso. Rio de Janeiro: Estação Brasil, 2019.

STRECK, Lenio Luiz; ABBOUD, Georges. O que é isto - o precedente judicial e as súmulas vinculantes? Porto Alegre: Livraria do Advogado Editora, 2013.

STURZA, Janaína Machado; SANTOS, Karinne Emanoela Goettems dos Santos. O bemcomum como valor e o acesso à justiça como compromisso: implicações sobre o processo civil. IN: Revista Direitos Humanos e Democracia da UNIJUÍ, V.2, N12, 2018. Disponível em: < file:///C:/Users/karin/Downloads/3838-371375394-1-PB\%20(1).pdf>. Acesso em: 30Jun.2020.

TARUFFO, Michele. Precedente e jurisprudência. IN: Civilistica.com, a. 3, n. 2, jul./dez./2014. Disponível em: <http://civilistica.com/precedente-e-jurisprudencia/>. Acesso em: 18/09/2019.

VIANA, Antônio Aurélio de Souza; NUNES, Dierle. Precedentes: a mutação do ônus argumentativo. Rio de Janeiro: Forense, 2018.

ZANETI JR, Hermes. $O$ valor vinculante dos precedentes: teoria dos precedentes normativos formalmente vinculantes. Salvador: JusPodivm, 2019.

Data de Submissão: 11/10/2020

Data de Aceite: 11/03/2021 